\title{
openheart On-X versus St Jude Medical Regent mechanical aortic valve prostheses: early haemodynamics
}

\author{
Robert Xu, ${ }^{1}$ Mohammad Rahnavardi, ${ }^{1}$ Bradley Pitman, ${ }^{2}$ Masoumeh Shirazi, ${ }^{2}$ \\ Robert Stuklis, ${ }^{1}$ James Edwards, ${ }^{1}$ Michael Worthington ${ }^{1}$
}

\begin{abstract}
To cite: Xu R, Rahnavardi M, Pitman B, et al. On-X versus St Jude Medical Regent mechanical aortic valve prostheses: early haemodynamics. Open Heart 2017;4:e000539. doi:10.1136/ openhrt-2016-000539
\end{abstract}

- Prepublication history is available. To view please visit the journal (http://dx.doi.org/10. 1136/openhrt-2016-000539).

Received 25 September 2016 Revised 20 November 2016 Accepted 28 November 2016

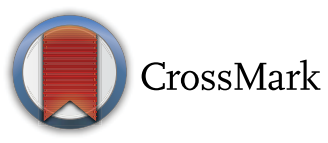

'D'Arcy Sutherland Cardiothoracic Surgical Unit, Royal Adelaide Hospital, Adelaide, South Australia, Australia

${ }^{2}$ Cardiology Unit, Royal Adelaide Hospital, Adelaide, South

Australia, Australia

Correspondence to Dr Mohammad Rahnavardi; rahnavardi@gmail.com

\section{ABSTRACT}

Objective We aimed to compare the early haemodynamic data of the On-X and St Jude Medical (SJM) Regent bileaflet mechanical prostheses in the aortic position. Methods A retrospective study was performed using data collected prospectively for a national database. Thirtythree patients who had aortic $0 n-X$ valve (On-X group) and 33 matched patients who had aortic SJM Regent valve (SJM group) were included. The intraoperative and early postoperative data were collected. The same echocardiographer reviewed all the echocardiograms and obtained the required parameters.

Results The peak gradient across the prosthetic valve was comparable between the two groups except for the labelled valve size of $25 \mathrm{~mm}$ for which the $0 \mathrm{n}-\mathrm{X}$ group had lower peak gradient when compared with the SJM group. Mean gradients and effective orifice area indices of the two valve types within each valve size subgroup were comparable.

Conclusions The current study confirms that in the early postoperative period, the two valve types had comparable haemodynamic outcomes.

\section{INTRODUCTION}

Aortic valve stenosis is the most common valvular heart disease internationally. Aortic regurgitation can be due to congenital conditions such as bicuspid valve, or acquired as in rheumatic heart disease, which remains prevalent in the Australian Aboriginal population. Despite the introduction of transcatheter-based techniques, surgical aortic valve replacement (AVR) remains the gold standard if the patient is deemed suitable by the heart valve team. Regarding prosthesis type, the current American College of Cardiology and American Heart Association guidelines state that mechanical valve prosthesis remains the 'standard of care' for patients less than 60 years of age who do not have a contraindication to anticoagulation, and reasonable to consider in those aged between 60 and 70 years. ${ }^{1}$

St Jude Medical (SJM) Regent (St Jude Medical, St Paul, Minnesota, USA) bileaflet mechanical prosthesis has demonstrated excellent early and long-term haemodynamic

\section{KEY QUESTIONS}

What is already known about this subject?

- Haemodynamic data from other studies/institutes are available and summarised in the Introduction and Discussion sections of this paper. Most data are from selected group of patients rather than 'all comers'.

What does this study add?

- In this study, we are presenting our achieved early haemodynamics with the $O \mathrm{n}-\mathrm{X}$ valve as compared with an alternative, more commonly used valve in our institute, namely, the St Jude Medical Regent aortic mechanical prosthetic valve. This is 'real life' data from 'all comers' in our institute rather than selected group of patients.

How might this impact on clinical practice?

- We believe clinicians require unbiased data from different institutes before they can recommend this valve type to their patients, and this paper can add to the pool of data available in the literature.

results $^{2-4}$ and has been routinely used in our institute. Good outcome after implantation of these valves, even in smaller aortic annuli, has been reported. ${ }^{5-7}$

The On-X bileaflet mechanical valve (On-X Life Technologies, Austin, Texas, USA) has a number of design features including manufacture from pure pyrolytic carbon, a flared inlet and an increased height to cylinder ratio. ${ }^{8}$ There have been a number of proposed benefits published in the literature, including a lower required target international normalised ratio. ${ }^{10}$ Previous results have suggested good haemodynamic performances. ${ }^{11}$ The On-X valve has been increasingly implanted during the study period in our institute.

The aim of this study was to compare the early haemodynamic data of the On-X and the SJM Regent bileaflet mechanical prostheses. 


\section{METHODS}

A retrospective study was performed using data collected prospectively for a national database. All patients with mechanical AVR through standard median sternotomy in our institute were reviewed. Between February 2011 and June 2015, 403 patients had bioprosthetic AVR and 86 had mechanical AVR. The operating surgeons were deciding on the choice of mechanical valves, and all surgeons were implanting either of the two valves. There was no institutional policy on the choice of valve. However, there was a tendency for using more SJM Regent valves in smaller aortic annuli by some surgeons. Thirty-three patients had AVR using an On-X mechanical valve (On-X group) and were included in this study. Thirty-three age-matched and body surface area (BSA)-matched patients who had AVR using SJM Regent mechanical aortic valve (SJM group) during the same time period were included as the control group. Baseline characteristics were collected for each group (table 1). The intraoperative data and early postoperative data were collected using the national database as well as the patient records.

\section{Echocardiographic measurements}

All patients had preoperative transthoracic echocardiogram and early postoperative echocardiogram within 2 weeks after operation. Echocardiographic views with two-dimensional cineloops, M-Mode and color Doppler were obtained. The same echocardiographer reviewed all the echocardiograms and obtained the required parameters following the guidelines of the American Society of Echocardiography. ${ }^{12}$ Measurements were performed offline using Philips Xcelera software (Amsterdam, the Netherlands). Peak pressure gradient was calculated using the maximum systolic trans-prosthetic flow velocity in the simplified Bernoulli equation, $4 \times(\operatorname{Vmax})^{2}$ formula. Mean pressure gradient was calculated from area under the curve of the systolic trans-prosthetic flow spectrum, the $4 \times\left(\sum \mathrm{V} 1+\mathrm{V} 2 \ldots+\mathrm{Vn}\right)^{2}$ formula. Effective orifice area (EOA) was calculated with continuity equation, $\Pi r^{2} \times \mathrm{LVOT} / \mathrm{max}$ formula, where LVOT stands for left ventricular outflow tract. The EOA was then indexed per BSA. Cross-sectional area was calculated with $\Pi r^{2}$ formula. The diameter of the LVOT was measured independently using the left parasternal long axis views.

\section{Operative information}

All procedures were performed through median sternotomy. Normothermic cardiopulmonary bypass (CPB) was used for all surgeries unless prolonged concomitant procedures were required. Myocardial protection was performed using intermittent cold blood cardioplegia solution. All valves were implanted in the supranular position. Transesophageal echocardiography was routinely performed before separation from CPB to examine valve function, to exclude paravalvular leak and to assist in deairing of the heart.
Table 1 Patient demographics and preoperative data

\begin{tabular}{|c|c|c|c|}
\hline & $\begin{array}{l}\text { On-X group, } \\
n=33\end{array}$ & $\begin{array}{l}\text { St Jude } \\
\text { Medical } \\
\text { Regent } \\
\text { valve } \\
\text { group, } \\
\mathrm{n}=33\end{array}$ & p Value \\
\hline Female, n (\%) & $6(18.2)$ & $9(27.3)$ & 0.279 \\
\hline Age, years (SD) & $50.4(14.3)$ & $55.3(7.5)$ & 0.216 \\
\hline $\begin{array}{l}\text { Body surface area, } \mathrm{m}^{2} \\
\text { (SD) }\end{array}$ & $2.0(0.3)$ & $2.0(0.3)$ & 0.200 \\
\hline Diabetes, n (\%) & $4(12.1)$ & $15(45.5)$ & 0.003 \\
\hline Hypertension, n (\%) & $13(39.4)$ & $22(66.7)$ & 0.028 \\
\hline Hyperlipidaemia, n (\%) & $10(30.3)$ & $18(54.5)$ & 0.048 \\
\hline $\begin{array}{l}\text { Renal failure requiring } \\
\text { dialysis, } n(\%)\end{array}$ & $0(0)$ & $1(3.0)$ & 0.317 \\
\hline
\end{tabular}

Peripheral vascular

disease, $\mathrm{n}(\%)$

\begin{tabular}{|c|c|c|c|}
\hline $\begin{array}{l}\text { Chronic obstructive } \\
\text { pulmonary disease, } n \\
\text { (\%) }\end{array}$ & $4(12.1)$ & $7(21.2)$ & 0.325 \\
\hline $\begin{array}{l}\text { Cerebrovascular } \\
\text { accident, } \mathrm{n}(\%)\end{array}$ & $1(3.0)$ & $0(0)$ & 0.317 \\
\hline $\begin{array}{l}\text { Coronary artery disease, } \\
\mathrm{n}(\%)\end{array}$ & 7 (21.2) & $12(36.4)$ & 0.174 \\
\hline NYHA class, n (\%) & & & 0.128 \\
\hline NYHA 1 & $1(3.0)$ & $0(0)$ & \\
\hline NYHA 2 & $16(48.5)$ & $11(33.3)$ & \\
\hline NYHA 3 & 14 (42.4) & 19 (57.6) & \\
\hline NYHA 4 & $2(6.1)$ & $3(9.1)$ & \\
\hline $\begin{array}{l}\text { Peak gradient, } \mathrm{mm} \mathrm{Hg} \\
(\mathrm{SD})^{*}\end{array}$ & $82.8(26.1)$ & $78.2(18.9)$ & 0.637 \\
\hline $\begin{array}{l}\text { Mean gradient, mm Hg } \\
(\mathrm{SD})^{\star}\end{array}$ & $56.9(16.5)$ & $47.5(10.9)$ & 0.159 \\
\hline $\begin{array}{l}\text { Aortic valve area, } \mathrm{m}^{2} \\
(\mathrm{SD})^{*}\end{array}$ & $0.80(0.26)$ & $0.85(0.15)$ & 0.975 \\
\hline $\begin{array}{l}\text { Reduced left ventricular } \\
\text { ejection fraction }(<50 \%) \text {, } \\
n(\%)\end{array}$ & $3(9.1)$ & $5(15.1)$ & 0.319 \\
\hline Valve lesion, $\mathrm{n}(\%)$ & & & 0.317 \\
\hline Aortic stenosis & $13(39.4)$ & $17(56.7)$ & \\
\hline Aortic regurgitation & $15(45.5)$ & $11(36.7)$ & \\
\hline Mixed disease & $5(15.2)$ & $2(6.7)$ & \\
\hline
\end{tabular}

*Patients with isolated aortic regurgitation are excluded from this calculation.

Significant $\mathrm{p}$ values are highlighted.

NYHA, New York Heart Association.

\section{Statistical analysis}

Numerical variables are presented as mean \pm SD if the distribution was parametric. Median and range were used to present numerical variables with non-parametric distribution. Categorical variables are presented as percentages. Non-parametric Mann-Whitney $\mathrm{U}$ test was used to test 


\begin{tabular}{|c|c|c|c|}
\hline & $\begin{array}{l}\text { On-X } \\
\text { group, } \\
n=33\end{array}$ & $\begin{array}{l}\text { St Jude } \\
\text { Medical valve } \\
\text { group, } \\
\mathrm{n}=33\end{array}$ & p Value \\
\hline Operation, n (\%) & & & 0.097 \\
\hline Isolated AVR & 19 (57.6) & 17 (51.5) & \\
\hline $\mathrm{AVR}+\mathrm{CABG}$ & $3(9.1)$ & $10(30.3)$ & \\
\hline $\begin{array}{l}\text { AVR+Mitral valve } \\
\text { surgery }\end{array}$ & $4(12.1)$ & $5(15.2)$ & \\
\hline Redo AVR & $3(9.1)$ & $0(0)$ & \\
\hline $\begin{array}{l}\text { AVR+2 other valvular } \\
\text { surgeries }\end{array}$ & $2(6.1)$ & $1(3.0)$ & \\
\hline $\begin{array}{l}\text { AVR+ another cardiac } \\
\text { operation }\end{array}$ & $2(6.1)$ & $0(0)$ & \\
\hline $\begin{array}{l}\text { Cardiopulmonary bypass } \\
\text { time, median (range)* }\end{array}$ & $\begin{array}{l}76.0 \\
(33-127)\end{array}$ & $72.0(36-141)$ & 0.824 \\
\hline $\begin{array}{l}\text { Cross clamp time, median } \\
\text { (range) }{ }^{*}\end{array}$ & $\begin{array}{l}61.0 \\
(27-104)\end{array}$ & $57.0(27-112)$ & 0.975 \\
\hline
\end{tabular}

*In patients with isolated AVR only.

AVR, aortic valve replacement; CABG, coronary artery bypass grafting.

numerical variables. The $\chi^{2}$ test or Fisher's exact test was used to test categorical variables. Statistical significance was assumed at $p \leq 0.05$. The IBM SPSS Statistics (Chicago, Illinois, USA) was used to perform statistical analyses.

\section{RESULTS}

Patients were matched for age and BSA. The frequencies of diabetes, hypertension and hyperlipidaemia were significantly higher in the SJM group than in the On-X group. However, the two groups were comparable in preoperative dyspnoea symptom and their aortic valve haemodynamics (table 1). More than $50 \%$ of patients had isolated AVR, and the rest had AVR combined with other procedures. In patients with isolated AVR, the cross clamp and the CPB times were not significantly different between the two groups (table 2). Labelled valve sizes 19 to $27 \mathrm{~mm}$ were used in each group (figure 1).

\section{Early postoperative haemodynamic results}

The subgroups of each valve size within the On-X and SJM groups were compared in terms of their early postoperative prosthetic aortic valve haemodynamics (table 3). The peak gradient across the prosthetic valve was significantly higher in the SJM group than in the On-X group for the labelled valve size $25 \mathrm{~mm}$. The same comparison for other valve sizes did not show any significant difference (table 3). Mean gradients of the two valve types within each valve size subgroup were comparable (figure 2). Similarly, there were no significant differences in the effective orifice area indices within each valve size between the two groups of this study (table 3 ).

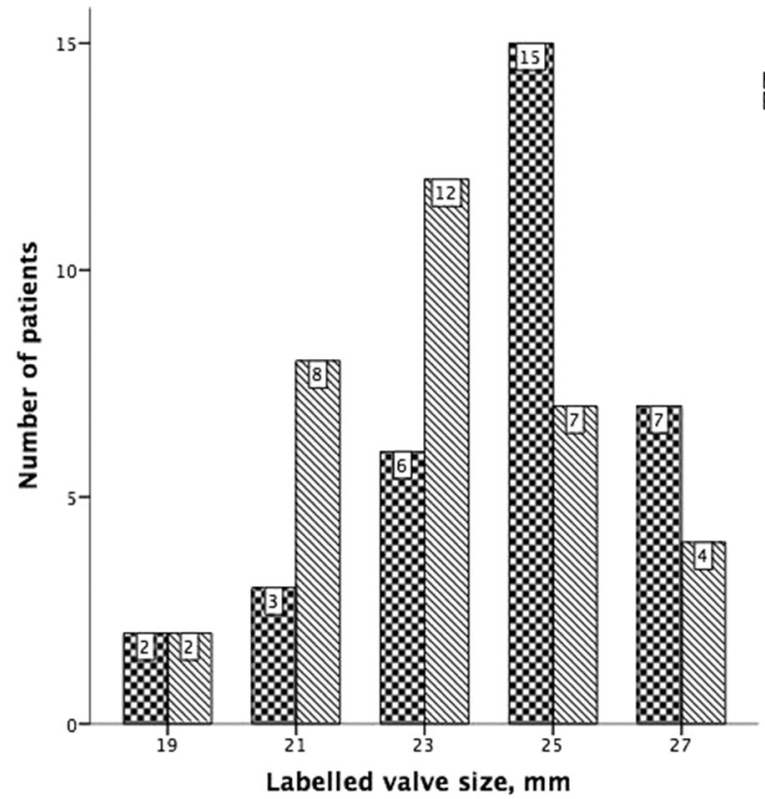

Figure 1 Distribution of patients between the two valve types for each labelled valve size. SJM, St Jude Medical.

\section{DISCUSSION}

The current study was designed to assess the early haemodynamic characteristics of the On-X valve as compared with another bileaflet aortic mechanical valve, namely, the SJM Regent aortic mechanical prosthetic valve. The two groups were matched for age and BSA. The haemodynamic data were not significantly different between the two groups. Similar results were reported from another centre, comparing the SJM Masters HP valve and the On-X valve. ${ }^{13}$ Another study suggested satisfactory early haemodynamic measurements of the On-X valve as compared with the literature values for the SJM prosthesis. ${ }^{14}$ A statistically significant lower peak gradient was observed after implantation of size $25 \mathrm{~mm}$ On-X valve compared with that of the same size SJM Regent valve. The same difference was not observed in other haemodynamic indices or between other smaller or larger valve sizes and is likely related to a small sample size not powered enough for such a comparison.

The SJM Regent valve has been the standard valve in use at our institute prior to introduction of the On-X aortic prosthesis. These valves are shown to provide excellent early ${ }^{2}$ and long-term ${ }^{3}$ haemodynamic results with stable haemodynamics in the first year after implantation. ${ }^{4}$ It has a higher orifice to annulus ratio than predecessor valves such as the SJM Masters HP, yet the suggestion for its use in small aortic roots. ${ }^{6}$ The $19 \mathrm{~mm}$ SJM Regent has been shown to have a larger effective orifice area than a $19 \mathrm{~mm}$ On-X valve. ${ }^{15}$ In our limited number of patients, the two valves showed similar haemodynamics, although there was a tendency for using more SJM Regent valves in smaller sized roots by some surgeons in our unit.

The On-X mechanical aortic valve has displayed a number of potential benefits, including low adverse clinical event rates including thromboembolism at 
Table 3 Early postoperative echocardiogram parameters, mean (SD)

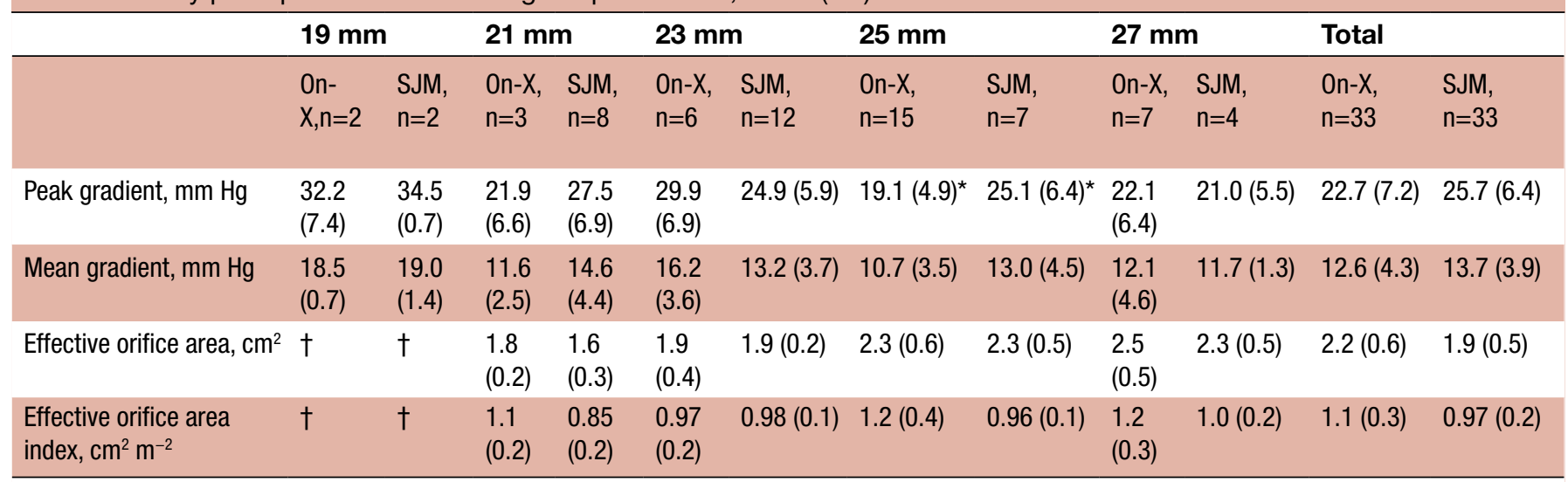

* $p=0.04$, Mann-Whitney U test comparing the peak gradient between the ONX and SJM patients with a $25 \mathrm{~mm}$ valve size.

†Data not available.

SJM, St Jude Medical.

short-, intermediate- and longer-term follow-up. ${ }^{16-21}$ A multicentric, prospective, non-randomised study was conducted in 11 European centres including 184 patients with On-X aortic prosthesis. Echocardiographic measurements of aortic peak pressure gradient, mean pressure gradient and EOA were $15.9 \pm 4.8 \mathrm{~mm} \mathrm{Hg}$, $8.3 \pm 2.9 \mathrm{~mm} \mathrm{Hg}$ and $1.53 \pm 0.26 \mathrm{~cm}^{2}$ for $19 \mathrm{~mm}$ valves $(\mathrm{n}=13) ; 14.7 \pm 6.6 \mathrm{~mm} \mathrm{Hg}, 7.8 \pm 3.4 \mathrm{~mm} \mathrm{Hg}$ and $2.01 \pm 0.48$ $\mathrm{cm}^{2}$ for $21 \mathrm{~mm}$ valves $(\mathrm{n}=22) ; 12.3 \pm 6.2 \mathrm{~mm} \mathrm{Hg}$, $6.6 \pm 3.2 \mathrm{~mm} \mathrm{Hg}$ and $2.31 \pm 0.79 \mathrm{~cm}^{2}$ for $23 \mathrm{~mm}$ valves $(\mathrm{n}=55)$; and $9.3 \pm 5.1 \mathrm{~mm} \mathrm{Hg}, 4.7 \pm 2.8 \mathrm{~mm} \mathrm{Hg}$ and

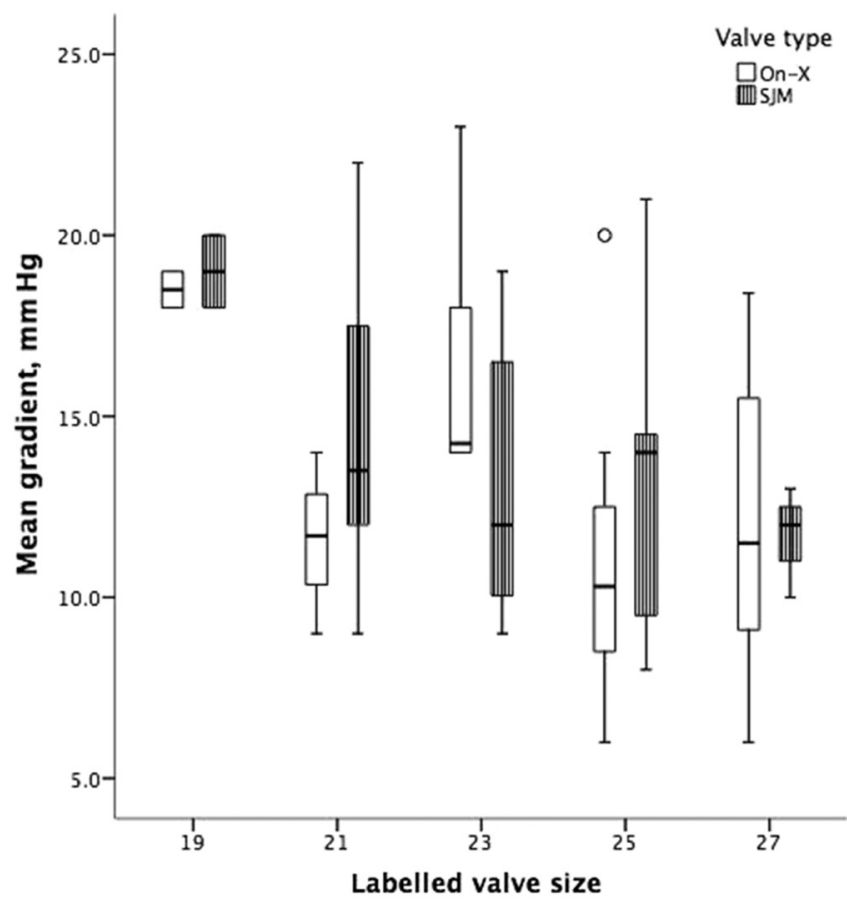

Figure 2 Early mean gradient for each valve type within each labelled valve size. SJM, St Jude Medical.
$2.75 \pm 0.75 \mathrm{~cm}^{2}$ for $25 \mathrm{~mm}$ valves $(\mathrm{n}=47)$, respectively. ${ }^{22}$ The early postoperative haemodynamic results of the On-X group of our study was worse than the results expected as per the company charts ${ }^{8}$ and some previous reports. ${ }^{11} 1622$ The difference in patient population and inclusion of patients with a mix of valvular heart disease may explain the discrepancy between our results and some other studies. Nevertheless, our results represent a 'real-life' single-institute experience with these prosthetic valves.

\section{LIMITATIONS}

This study is limited by its relatively small sample size especially in each valve size category and its retrospective design. To minimise the effects of these limitations, we matched the two groups based on age and BSA. Furthermore, for the purpose of this study, the echocardiographic data are obtained by the same echocardiographer reviewing the archive of the echocardiograms of all patients included in this study.

\section{CONCLUSION}

Our study confirms that in the early postoperative period, the two valve types had comparable haemodynamic outcomes. Further prospective randomised trials are required to validate the findings of the current study. Funding Royal Adelaide Hospital paid the publication fee.

Competing interests None declared.

Competing interests Local ethics committee approved this study.

Provenance and peer review Not commissioned; externally peer reviewed.

Data sharing statement The SPSS datasheet is available.

Open Access This is an Open Access article distributed in accordance with the Creative Commons Attribution Non Commercial (CC BY-NC 4.0) license, which permits others to distribute, remix, adapt, build upon this work non-commercially, and license their derivative works on different terms, provided the original work 
is properly cited and the use is non-commercial. See: http://creativecommons.org/ licenses/by-nc/4.0

(c) Article author(s) (or their employer(s) unless otherwise stated in the text of the article) 2017. All rights reserved. No commercial use is permitted unless otherwise expressly granted.

\section{REFERENCES}

1. Nishimura RA, Otto CM, Bonow RO, et al; American College of CardiologyAmerican College of Cardiology/American Heart AssociationAmerican Heart Association. AHA/ACC guideline for the management of patients with valvular heart disease: a report of the American College of Cardiology/American Heart Association Task Force on Practice Guidelines. J Thorac Cardiovasc Surg 2014;148:e1-132.

2. Bach DS, Goldbach M, Sakwa MP, et al; SJM Regent Study Group. Hemodynamics and early performance of the St. Jude medical Regent aortic valve prosthesis. J Heart Valve Dis 2001;10:436-42.

3. Nishida T, Sonoda H, Oishi Y, et al. Long-term comparison of three types of aortic St. Jude Medical mechanical prosthesis in Japanese patients. Circ J 2015;79:2193-200.

4. Offstad J, Andersen K, Paulsson P, et al. The Scandinavian multicenter hemodynamic evaluation of the SJM Regent aortic valve. J Cardiothorac Surg 2011;6:163.

5. Pisano C, D'Amico T, Palmeri C, et al. Valve prosthesis-patient mismatch: hemodynamic, echocardiographic and clinical consequences. Interact Cardiovasc Thorac Surg 2011;13:606-10.

6. Prifti E, Bonacchi M, Baboci A, et al. Hemodynamics of $17-\mathrm{mm}$ vs. 19-mm St. Jude Medical Regent and annulus enlargement. Asian Cardiovasc Thorac Ann 2015;23:670-83.

7. Zhao D, Wang C, Hong T, et al. Application of regent mechanical valve in patients with small aortic annulus: 3-year follow-up. $J$ Cardiothorac Surg 2012;7:88.

8. On-X Life Technologies Inc. On-X heart prosthetic heart valve. http:// www.onxlti.com/ifu/hv (accessed 18 Dec 2015). http://www.onxlti. com/wp/wp-content/uploads/2015/01/01012202O.pdf (accessed 18 Dec 2015).

9. Akutsu T, Matsumoto A. Influence of three mechanical bileaflet prosthetic valve designs on the three-dimensional flow field inside a simulated aorta. J Artif Organs 2010;13:207-17.

10. Puskas J, Gerdisch M, Nichols D, et al; PROACT Investigators. Reduced anticoagulation after mechanical aortic valve replacement: interim results from the prospective randomized on-X valve anticoagulation clinical trial randomized Food and Drug Administration investigational device exemption trial. $J$ Thorac Cardiovasc Surg 2014;147:1202-11.

11. Chambers J, Ely JL. Early postoperative echocardiographic hemodynamic performance of the On-X prosthetic heart valve: a multicenter study. J Heart Valve Dis 1998;7:569-73.

12. Zoghbi WA, Chambers JB, Dumesnil JG, et al; American Society of Echocardiography's Guidelines and Standards Committee
Task Force on Prosthetic Valves American College of Cardiology Cardiovascular Imaging Committee Cardiac Imaging Committee of the American Heart Associati on European Association of Echocardiography European Society of Cardiology Japanese Society of Echocardiography Canadian Society of Echocardiography American College of Cardiology Foundation American Heart Association. Recommendations for evaluation of prosthetic valves with echocardiography and doppler ultrasound: a report from the american Society of Echocardiography's Guidelines and Standards Committee and the Task Force on Prosthetic Valves, developed in conjunction with the American College of Cardiology Cardiovascular Imaging Committee, Cardiac Imaging Committee of the American Heart Association, the European Association of Echocardiography, a registered branch of the European Society of Cardiology, the Japanese Society of Echocardiography and the Canadian Society of Echocardiography, endorsed by the American College of Cardiology Foundation, American Heart Association, European Association of Echocardiography, a registered branch of the European Society of Cardiology, the Japanese Society of Echocardiography, and Canadian Society of Echocardiography. J Am Soc Echocardiogr 2009;22:975-1014.

13. Walther T, Falk V, Tigges R, et al. Comparison of On-X and SJM HP bileaflet aortic valves. $J$ Heart Valve Dis 2000;9:403-7.

14. Fraund $\mathrm{S}$, Pethig $\mathrm{K}$, Wahlers $\mathrm{T}$, et al. On-X bileaflet valve in aortic position---early experience shows an improved hemodynamic profile. Thorac Cardiovasc Surg 1998;46:293-7.

15. Bottio T, Caprili L, Casarotto D, et al. Small aortic annulus: the hydrodynamic performances of 5 commercially available bileaflet mechanical valves. J Thorac Cardiovasc Surg 2004;128:457-62.

16. Moidl R, Simon P, Wolner E, On-X Prosthesis Heart Valve Trial. The On-X prosthetic heart valve at five years. Ann Thorac Surg 2002;74:S1312-7.

17. Ozyurda U, Akar AR, Uymaz O, et al. Early clinical experience with the On-X prosthetic heart valve. Interact Cardiovasc Thorac Surg 2005;4:588-94.

18. McNicholas KW, Ivey TD, Metras J, et al. North American multicenter experience with the On-X prosthetic heart valve. $J$ Heart Valve Dis 2006;15:73-8.

19. Tossios $P$, Reber D, Oustria M, et al. Single-center experience with the On-X prosthetic heart valve between 1996 and 2005. J Heart Valve Dis 2007;16:551-7.

20. Chan V, Jamieson WR, Lam BK, et al. Influence of the On-X mechanical prosthesis on intermediate-term major thromboembolism and hemorrhage: a prospective multicenter study. $J$ Thorac Cardiovasc Surg 2010;140:1053-8.

21. Chambers JB, Pomar JL, Mestres CA, et al. Clinical event rates with the On-X bileaflet mechanical heart valve: a multicenter experience with follow-up to 12 years. J Thorac Cardiovasc Surg 2013;145:420-4.

22. Palatianos GM, Laczkovics AM, Simon P, et al. Multicentered European study on safety and effectiveness of the On-X prosthetic heart valve: intermediate follow-up. Ann Thorac Surg 2007;83:40-6. 